\title{
Políticas linguísticas e internacionalização da língua portuguesa: desafios para a inovação
}

\section{Language policies and the internationalization of the Portuguese language: challenges to innovation}

Maria Helena da Nóbrega

USP

mhn135@gmail.com

Resumo: Este artigo objetiva expor a compreensão vigente sobre políticas linguísticas, com o propósito de ampliar a divulgação do tema, merecedor de destaque nas pesquisas atuais da Linguística Aplicada. Após explicar a importância atribuída às línguas no sistema de produção da atualidade e a consequente valorização do multilinguismo, o texto apresenta políticas linguísticas no plano doméstico e no contexto externo, com ênfase para as ações de internacionalização da língua portuguesa. O resultado dessa abordagem mostra o aprimoramento das práticas de divulgação da língua portuguesa no exterior, antes restritas à tradução de renomados autores brasileiros. A conclusão revela que é preciso inovar o projeto pedagógico dos programas de pós-graduação, com vistas a formar profissionais que possam atuar nas esferas de decisão das políticas linguísticas. Tal inovação deve ser iniciada pela incorporação de estudo sobre questões éticas e ideológicas às linhas de pesquisa da pós-graduação, que reforçaria o estreitamento entre raciocínio histórico-discursivo e abordagem linguística, indo além da descrição abstrata do sistema da língua.

Palavras-chave: políticas linguísticas; internacionalização; língua portuguesa. 
Abstract: This article aims at presenting the current understanding of language policies, in order to broaden the knowledge about this topic, which is worthy of emphasis in current research in Applied Linguistics. After explaining the importance attached to languages in the system of production at present, and the resulting importance of multilingualism, the paper addresses language policies both in the domestic scenario and abroad, stressing actions for the internationalization of Portuguese. The result of this approach points to the improved practices for promoting Portuguese abroad, which had previously been restricted to the translation of reputed Brazilian authors. The conclusion indicates that it is necessary to innovate the political pedagogical project of graduate programs, in order to train professionals who can serve in decision-making of language policies. Such innovation should be initiated by an inclusion of the study of ethical and ideological issues in the research areas of graduate programs, which would then strengthen the nearness of historical and discursive knowledge and the linguistic approach, thus transcending the abstract description of the language system.

Keywords: language policies; internationalization; Portuguese language.

Recebido em 06 de junho de 2015. Aprovado em 06 de julho de 2015.

\section{Introdução}

Clima de festa, MPB tocando baixinho, pessoas conversando num misto de animação e timidez. Beijinhos, abraços ou apertos de mão diversificam os cumprimentos na chegada de estudantes, professores e demais convidados. $\mathrm{O}$ interesse pelo Brasil une esse grupo de pessoas de diferentes nacionalidades. $\mathrm{O}$ amor à cultura brasileira trouxe-os para o centro de Londres, para assistir à exibição do filme Orgulho de ser brasileiro (The pride of being Brazilian), patrocinado pelo Instituto Brasileiro do King's College, unidade da Universidade de Londres. O documentário apresenta entrevistas com personalidades públicas como o ex-presidente Fernando Henrique Cardoso, o artista plástico Romero Britto, o técnico de futebol Carlos Alberto Parreira, a ex-ministra do Meio Ambiente Marina Silva, a geneticista Mayana Zatz, entre outros. 
No final do evento, Adalberto Piotto, diretor da película, troca ideias com o público sobre a produção desse filme.

Esse evento ilustra a expressividade alcançada pela cultura brasileira no cenário internacional. Episódios como esse se somam a muitos outros realizados pelas embaixadas, centros de estudos brasileiros e institutos culturais, e ilustram a divulgação da cultura brasileira no exterior.

Com a visibilidade da cultura, ocorre a expansão da língua portuguesa de forma inimaginável, mesmo para os ambiciosos navegadores portugueses do século 15, que transportaram o idioma nas viagens marítimas. Hoje há cursos de língua portuguesa em diversas nações, fora das que compõem a Comunidade dos Países de Língua Portuguesa (CPLP): Angola, Brasil, Cabo Verde, Guiné Bissau, Moçambique, Portugal, São Tomé e Príncipe e Timor Leste. Nas populações africanas, o português dialoga com mais de 300 línguas.

Além desses países, outros dois também instituíram o português como língua oficial: Guiné Equatorial, na África Ocidental, e Macau, na China. Isso totaliza dez países que têm a língua portuguesa reconhecida pelo Estado e, portanto, usam-na em documentos oficiais, repartições públicas, rede escolar e em toda a mídia. $\mathrm{O}$ alcance da língua portuguesa, no entanto, não se restringe ao espaço territorial desses países.

Há cursos de língua portuguesa em vários locais do mundo, sendo praticamente impossível contabilizá-los em sua totalidade, pois eles são realizados em escolas de idioma ou em aulas particulares, presenciais ou a distância. Para efeito de delimitação, venho pesquisando esse universo internacional de cursos de português especificamente em instituições de ensino superior (IES). São cursos regulares oferecidos no programa de várias escolas, por exemplo: nas universidades de Yale, Princeton, Cornell, Brown, Georgetown (EUA), Oxford e Cambridge (Inglaterra), Estocolmo (Suécia), Aarhus (Dinamarca), Oslo (Noruega), Salamanca (Espanha) etc. Na América Latina, o Mercosul, cujo tratado foi assinado em 1991, fortaleceu o ensino de língua portuguesa.

Longe de esgotar esse universo, este texto se interessa por apresentar ações governamentais e institucionais de internacionalização da língua portuguesa do Brasil. Como esse tema está diretamente relacionado ao comportamento dos idiomas no intricado mercado linguístico da atualidade, o texto inicialmente expõe a importância das línguas nesse início do século 21. 
Além disso, a abordagem aqui proposta leva em conta a pouca visibilidade do objeto na divulgação acadêmica. O termo política, por si só, parece pouco atraente, numa possível acomodação ao sentido mais reconhecido do vocábulo política em termos gerais. Pensa-se na política como algo externo a si mesmo, como algo que se define nas altas esferas, por autoridades designadas para tal, e não como algo do dia a dia, que sofre influência dos indivíduos. Essa alienação faz com que muitos cidadãos não tomem partido e sintam-se apartados de qualquer tipo de política. "Política não se discute", diz o provérbio popular, o que inibe intervenções na política educacional, política linguística, política salarial, política habitacional, política ambiental, política monetária, política tributária, política de segurança e demais mediações na sociedade, pois todas as ações são, afinal, ações políticas.

Internacionalização também é matéria ainda pouco explorada nas pesquisas acadêmicas. $\mathrm{O}$ termo aparece frequentemente associado a dois temas prioritários na agenda da educação atual: 1) internacionalização da língua, no sentido de propagar o idioma em escala global; e 2) internacionalização de determinada instituição educacional, o que significa viabilizar redes de contato de professores e alunos com o objetivo de fomentar o desenvolvimento científico e tecnológico.

Para criar maior visibilidade internacional, os intercâmbios estudantis estão na rotina das instituições, preocupadas em se manter visíveis no concorrido mercado educacional da atualidade. Como exemplo, vale lembrar o Ciência sem Fronteiras, ambicioso programa de mobilidade para estudantes de graduação e pós-graduação.

Essas duas práticas de cooperação internacional-internacionalização linguística e internacionalização educacional-dependem de procedimentos que apenas recentemente começam a ser analisados, criticados, aperfeiçoados. Nos limites deste artigo, abordo a internacionalização da língua portuguesa do Brasil, sem deixar de mencionar o trabalho de divulgação do português europeu, realizado sobretudo pelo Instituto Camões, ligado ao Ministério dos Negócios Estrangeiros de Portugal (INSTITUTO CAMÕES, s. d.). No âmbito literário, Mia Couto, José Eduardo Agualusa e Ondjaki são alguns dos autores que têm contribuído para tornar conhecida a língua portuguesa e a cultura dos países africanos.

Dessa forma, a singularidade do tema - políticas linguísticas e internacionalização do português brasileiro - impõe que inicialmente se considere a definição do objeto: o que são políticas linguísticas. Nesse 
quesito, apresento exemplos de políticas educacionais no plano doméstico brasileiro e, finalmente, no contexto externo, na internacionalização propriamente dita.

Além de ter como objetivo contribuir para a divulgação de matéria de extrema relevância para a linguística aplicada atual, intenciono demonstrar alguns problemas que permeiam as políticas públicas de internacionalização e, por fim, proponho ações que podem aprimorar o impacto da língua portuguesa no mercado mundial das línguas da contemporaneidade.

\section{Centralidade da gestão linguística}

Analisando o Quadro Europeu Comum de Referência para as línguas, Diniz declara que:

se, na Idade Moderna, a língua nacional era um elemento central para a construção da identidade nacional - e, assim, da própria cidadania-, na Contemporaneidade, a aprendizagem de diferentes línguas aparece como requisito para uma espécie de "cidadania transnacional", marcada pela discursividade do Mercado (2007, p. 368).

A produção tecnológica da atualidade criou um valor de destaque para as línguas. Isso decorre do fato de a informação, cada vez mais valiosa na organização econômica mundial, exigir conhecimento linguístico em todas as etapas de produção, manutenção, divulgação e incorporação. A sociedade em rede é multidirecional e realça a capacidade de ler e escrever. Como resultado, temos profundas alterações no mercado de trabalho de uma forma geral, com implicações inegáveis para a área educacional.

Observamos que nunca a produção e reprodução das condições materiais de existência social exigiram tanto a participação do conhecimento e o desenvolvimento intelectual daqueles que atuam no processo produtivo. Por outro lado, a automação diminui o número de trabalhadores necessários à produção material, gerando uma massa cada vez maior de excluídos (mesmo que incluídos no acesso à Escola). É preciso, pois, elevar o nível intelectual dos trabalhadores para que possam acompanhar as mudanças tecnológicas e, ao mesmo tempo, limitá-lo só ao processo de reprodução da força de trabalho (SILVA, 2007, p. 12). 
Assim, à medida que o processo produtivo torna-se dependente da comunicação, essa nova forma de produção econômica atribui grande destaque às línguas, além de valorizar o multilinguismo, definido como a capacidade de a pessoa comunicar-se em várias línguas. Isso valoriza as competências linguísticas: dominar diversas línguas é fator diferencial de empregabilidade no contexto atual.

Em outras palavras, o mundo vivenciou muitas mudanças no campo educacional à luz da tecnologia da informação e globalização nas últimas três décadas. Como consequência, o foco do ensino de língua mudou de monolinguismo para bilinguismo e multilinguismo. Há muito mais bilíngues ou multilíngues do que monolíngues no mundo atual (SINGH, ZHANG, BESMEL, 2012, p. 354). ${ }^{1}$

Vale lembrar que o conjunto das línguas da atualidade não possui mais o caráter estável que persistia nos anos 1960. O fluxo linguístico intenso, inclusive, arrefeceu o valor hegemônico do idioma inglês como língua estrangeira. A configuração dos mercados globalizados põe foco na aprendizagem de outras línguas, notadamente o mandarim e o espanhol. O português também ganha espaço nesse panorama linguístico, conforme Oliveira:

A língua portuguesa é uma das línguas de mais rápido crescimento neste momento histórico, que representa, no entanto, um crescimento do multilinguismo de modo geral e das grandes línguas do mundo em particular, pelas características do atual estágio das forças produtivas, com grandes implicações para as mudanças no padrão da governança global (2013a, p. 418).

Há, portanto, uma indústria das línguas, tal como conceituada por Calvet (2007), e essa indústria se traduz na criação de dicionários, softwares, bases de dados, utilização da língua na internet, existência

\footnotetext{
${ }^{1}$ Minha tradução de: "In other words, the world has seen many changes in the field of education in the light of information technology and globalization over the past three decades. As a result, the focus of language education has shifted from monolingualism to bilingualism and multilingualism. There are many more bilinguals or multilinguals than monolinguals in the world now".
} 
de corretores ortográficos etc., material constantemente aprimorado por pesquisa multidisciplinar.

Isso torna plausível a constatação de Bourdieu (1998): a comunicação linguística é regida por forças simbólicas. No chamado mercado linguístico, as palavras, as línguas são bens que têm o valor que lhes é atribuído pela estrutura social, econômica e política.

Esse valor não é fixo, mas vai sendo construído pelas forças mercadológicas. A língua portuguesa, por exemplo, já é "língua de trabalho em organizações internacionais: União Europeia (EU), Mercosul, Unidade Africana (UA), União Latina (UL) e caminha para tornar-se um dos idiomas de trabalho da Organização Mundial do Turismo" (PESSOA, 2007, p. 2). Além disso, nos últimos anos a língua portuguesa tem visto crescer sua relevância internacionalmente, por conta da divulgação da música e, mais recentemente, da produção cinematográfica brasileira. Oliveira acrescenta outras razões para essa maior exposição.

O período pós-2004, que aqui nos interessa, tem sido um período virtuoso para o crescimento da língua portuguesa, tanto internamente como externamente. Ampliou-se o letramento da população, a inserção dos países na sociedade internacional, o crescimento da classe média, criando uma produção e um consumo cultural mais sofisticado, mais viagens ao exterior e maior acesso à Internet. Estes fatores fomentam um interesse maior pelos países de língua portuguesa e, consequentemente, maior disposição para o seu aprendizado como língua estrangeira (OLIVEIRA, 2013a, p. 417).

A procura por cursos de português no exterior resulta do valor crescente do idioma no mercado linguístico mundial.

\section{Motivações dos estrangeiros para aprender o português}

No mercado globalizado da atualidade, em que as línguas têm valor exponencial, várias razões motivam os estrangeiros a aprender o português.

Em primeiro lugar, temos os filhos de imigrantes lusófonos. Com conhecimento básico da língua, normalmente aprendido no contexto familiar, eles buscam aprofundamento linguístico que ultrapasse o 
envolvimento emocional que têm com a língua e a cultura. No geral, comunicam-se oralmente sobre temas do dia a dia, mas sentem-se inseguros nas práticas redacionais, apresentam problemas ortográficos e desconhecem gêneros textuais variados. Esse grupo quer desenvolver a língua de herança, e por isso busca aprendizado para as suas necessidades práticas, orais e escritas. Isso justifica por que é fundamental

avançar no planejamento de cursos, de materiais e de propostas para a formação de professores, de modo a contribuir para criar um corpo de conhecimento sobre o ensino de português em contexto de herança, não somente em países onde esse tipo de ação já está em curso, como nos Estados Unidos, mas também em outros nos quais as comunidades de herança emergem e reclamam por seu lugar nas línguas e culturas em português, como nos países do Oriente Médio e da Ásia, por exemplo (MENDES, 2014).

No segundo caso, estão os que foram cativados por produtos da cultura brasileira. Nesse quesito destacam-se as telenovelas brasileiras, dubladas em diversos países: "[...] 102 países já importaram as telenovelas brasileiras, considerando-se apenas os países que efetivamente firmaram contrato com as produtoras" (TONDATO, s. d., p. 4). O interesse pode advir também do gosto pela música brasileira, divulgada no exterior com bastante sucesso. Há ainda os que se envolvem com a cinematografia brasileira, produção que vem conquistando público no exterior, sobretudo a partir dos anos 1990, com Central do Brasil, de Walter Salles. Nesse caso, a sedução pelos bens culturais vem antes da afeição pela língua. Sem conhecimento prévio do idioma, essas pessoas inscrevem-se em cursos de nível básico da língua portuguesa.

O terceiro grupo de estrangeiros empenhado em aprender português é composto de profissionais de diversas áreas, interessados em atuar em empresas brasileiras com sede no exterior, ou em viver, estudar e trabalhar no Brasil.

Em geral, o aluno norte-americano interessado no Brasil se interessa por relações internacionais, administração, medicina. [...] Porque eles querem fazer pesquisa aqui, eles querem conhecer o mercado, participar de negócios. São alunos das ciências sociais ou das ciências econômicas, ou de direito, de programas de MBA (PASSOS, 2014, p. 14). 
Esse contingente tem aumentado devido ao fato de o Brasil manter a empregabilidade acima da média mundial, segundo a Organização Internacional do Trabalho (OIT). A terra de oportunidades e o povo generoso e solidário conquistam os estrangeiros, que facilmente se sentem atraídos também pela língua portuguesa. Esses profissionais procuram um ensino instrumental, voltado principalmente para a linguagem técnica da sua área de atuação.

Finalmente, buscam aprender o português profissionais que têm a língua como objeto de trabalho: tradutores, intérpretes, professores de português para estrangeiros. Necessitando de aprendizado global e nível alto de aperfeiçoamento, esses especialistas querem cursos que ofereçam particularidades do idioma, de forma a garantir sua atuação como profissionais da língua portuguesa. Esse ramo também tende a crescer, por exemplo, graças à necessidade de dubladores e redatores de legendas para a próspera produção audiovisual brasileira.

Esse público heterogêneo - filhos de imigrantes lusófonos, amantes da cultura brasileira, empresários, profissionais da área de comunicação e linguagem - se distribui em diferentes faixas etárias, têm interesses particulares cuja caracterização ainda não foi devidamente rastreada, inclusive porque "a historiografia do ensino do português no exterior ainda se encontra em estágio de produção incipiente" (LUNA, 2012, p. 33). O fato é que os cursos de português para estrangeiros no exterior e no Brasil precisam atender a essa coletividade, além de preencher suas expectativas iniciais em relação à cultura brasileira e língua portuguesa.

Não há dúvida de que o Brasil nunca desfrutou de tanta receptividade no exterior como nesse início do século 21. Frente aos problemas europeus da atualidade - permanente fluxo migratório, intolerância étnica e religiosa, posturas ultranacionalistas e xenofóbicas, cortes em programas sociais, aumento na taxa de desemprego, desigualdade social crescente-, o Brasil é visto como terra de oportunidades. Assim, é primordial compreender o que são políticas linguísticas e como se pode intervir na criação delas, para aproveitar esse panorama tão oportuno.

\section{Políticas linguísticas: conceitos e casos domésticos}

A partir da década de 1950, vários países africanos e asiáticos foram descolonizados. Isso promoveu o plurilinguismo, que fez 
surgir a necessidade de políticas linguísticas, ou seja, a necessidade de intervir sobre os destinos de uma língua, criando direcionamentos racionalmente elaborados. Essas intervenções "podem ser de dois tipos: sobre o corpus, quando se trata de propostas de intervenção sobre a forma de uma determinada língua, e sobre o status, quando é relativa à promoção de determinada língua num contexto de plurilinguismo" (CARVALHO, 2012, p. 463). Para Calvet (2007), essas intervenções são precisamente de ordem política e atuam em situações linguísticas concretas, por isso o autor dá exemplo de políticas linguísticas em vários países.

Para que a política surta efeito, ela depende de planejamento linguístico, ou seja, depende de ações sistêmicas que envolvam todos os atores que fazem parte do processo.

O planejamento de status está relacionado ao papel da língua, às funções que ela vai exercer, seu status social e suas relações com as outras línguas (como língua nacional, língua oficial, meio de instruções etc.). Por sua vez, o planejamento de corpus diz respeito às intervenções na forma ou variedade da língua que vai ser escolhida como modelo para a sociedade e promovida como tal (criação de um sistema de escrita, neologia, padronização). (CORREA, 2009, p. 74-75).

Além de corpus e status, há também as políticas de aquisição, diretamente relacionadas ao ensino. A criação das políticas educacionais, culturais e linguísticas é articulada principalmente pelo Estado e pode se destinar a contextos internos ou externos. Trata-se de uma maneira de assegurar "a exclusividade de legislar sobre as línguas com o objetivo de garantir o controle sobre as reivindicações e ações político-identitárias de seus cidadãos" (TORQUATO, 2010, p. 8).

Mesmo assim, a mobilização de comunidades específicas pode pressionar as autoridades, como foi o caso da regulamentação da Língua Brasileira de Sinais (LIBRAS), que agora já existe em cursos de licenciatura. Hoje a Universidade do Vale do Rio dos Sinos e a plataforma virtual Veduca oferecem curso via internet. ${ }^{2}$ Em $30 \mathrm{~h}$, o conteúdo introduz a cultura surda e noções básicas sobre Libras. A facilidade de acesso à plataforma virtual e as oito vídeoaulas são

${ }^{2}$ Cf. $<$ http://www.veduca.com.br/browse/universities/38>. 
fruto de trabalho persistente de profissionais para a implementação de políticas educacionais nessa área.

Outro exemplo de que as políticas linguísticas podem ser decisivamente influenciadas por ações de pessoas que não atuam na esfera governamental advém do último Censo Demográfico, realizado em 2010. Graças à intervenção de associações indígenas, linguistas e antropólogos, houve a inclusão de perguntas no questionário do universo, ou seja, perguntas que foram respondidas por todos os brasileiros que se declararam indígenas: 1) a que etnia pertence?; 2) qual o idioma indígena falado em casa? (HAAG, 2010).

Essas questões permitiram alterar dados precários sobre etnias, distribuição geográfica, padrões de migração, renda, escolaridade dos indígenas, trazendo à tona um retrato fiel da realidade do país e permitindo intervenção positiva em políticas públicas de demarcação de terra, saúde, educação etc.

Em termos linguísticos, foi possível obter a contabilização das línguas indígenas atuais: entre 150 a 180 línguas diferentes, das quais $21 \%$ estão ameaçadas de extinção, devido à baixa transmissão para as novas gerações.

Esses dois exemplos - sobre língua de sinais e sobre línguas indígenas - demonstram o jogo de poder implicado nas políticas linguísticas e a persuasão que grupos de profissionais organizados podem obter.

Outros tipos de políticas públicas também são foco de consideração, conforme Oliveira (2013, p. 1):

Há as políticas públicas que o governo tem interesse em publicizar, porque são signos de competência, trabalho, articulação e, frequentemente, rendem votos ao governante. Há as políticas públicas que são mais ou menos secretas ou confidenciais, como é o caso de muitos aspectos da política externa ou da política militar. Há, finalmente, um terceiro tipo de política pública, de pouca visibilidade, mas cuja invisibilidade não é derivada de uma intenção do Estado ou do governo. É o caso das políticas linguísticas.

Política e planejamento linguísticos ocupam os estudos acadêmicos desde os primeiros anos após a Segunda Guerra Mundial. Esses termos procuram 
diferenciar política linguística (isto é, o planejamento - leis, regulamentos, regras e pronunciamento ou protocolos de intenções-, que pode ser concreto ou simbólico) e o planejamento linguístico (isto é, a implementação - como os planejamentos são colocados em execução), embora esse termos sejam frequentemente usados de forma indistinta na literatura (BALDAUF JR., 2012, p. 234). ${ }^{3}$

Integrando a linguística aplicada, a disciplina que aborda as políticas e os planejamentos linguísticos atrela-se completamente às necessidades do século 21 em relação a direitos linguísticos, globalização, multilinguismo e multiculturalismo. No Brasil, a linguística começa a ter presença mais forte nas políticas educacionais a partir da década de 1970, anos marcados por diversas transformações sociais, como a conhecida "expansão e democratização do ensino fundamental no Brasil" (SILVA, 2007).

Historicamente têm prevalecido ações proibitivas na política linguística interna brasileira. Uma das primeiras ocorreu no século 18, quando o Marquês de Pombal, de seu escritório em Lisboa, determinou que todas as manifestações linguísticas no Brasil teriam que ocorrer em português. Foi uma ação contra a língua geral, de base tupi, em clara represália à relativa independência adquirida pela Companhia de Jesus, já que os jesuítas estavam influenciando de forma decisiva as políticas linguísticas colonizadoras. Esse episódio exemplifica claramente a tendenciosidade das políticas linguísticas, posto que o caráter político prevalece sobre razões linguísticas.

Este evento histórico determina em que medida se instala uma política de língua. Para a política da época, não só a presença dos jesuítas deixou de ser interessante, como também as línguas indígenas passaram a representar uma ameaça a algum aspecto da soberania da Coroa sobre terras brasileiras (LUQUETTI; MOURA; CASTELANO, 2011, p. 21).

\footnotetext{
${ }^{3}$ Minha tradução de: "[...] differentiates between language policy (i. e., the plan - the laws, regulations, rules and pronouncements or statements of intent - these may be substantive or symbolic) and language planning (i. e., the implementation - how plans are put into practice) although these terms are quite often used interchangeably in the literature".
} 
Desde essa época, o imaginário coletivo pensa o Brasil como um país monolíngue, o que faz silenciar as aproximadamente 200 línguas indígenas, as línguas das comunidades afro-brasileiras e as cerca de 20 línguas de imigração (CORREA, 2009), proibidas desde 1938 pela política de nacionalização do ensino, na era Vargas (ALTENHOFEN, 2004; FRITZEN, 2012).

Esse apagamento de línguas cria irrealidades na descrição das comunidades linguísticas, como é o caso notório da

\begin{abstract}
Austrália, que tem o inglês como língua oficial, mas quase um quinto da população falante de outro idioma como primeira língua, entre as quase 150 línguas aborígenes e em torno de 75 a 100 línguas de imigrantes. No final dos anos 1970, o primeiro ministro australiano formou um comitê para rever os programas e serviços voltados para os imigrantes, que viviam conflitos étnicos, trabalhavam em empregos mal remunerados e tinham baixos níveis de escolaridade (CUNHA, 2008, p. 147).
\end{abstract}

Atualmente uma das pautas em que estudiosos e planejadores investem é exatamente na mobilização para que o Brasil se assuma como país plurilíngue e pluricultural. Adotar mais de uma língua oficial seria um avanço em termo de políticas linguísticas, já que " $94 \%$ dos países do mundo, inclusive o Brasil, são plurilíngues" (OLIVEIRA, 2005, p. 87). A Suíça, por exemplo, assume quatro línguas oficiais: francês, alemão, italiano e romanche. Nosso vizinho Paraguai adota duas línguas oficiais: o espanhol e o guarani. O Brasil também precisa rever sua autoimagem de monolíngue, e assumir um retrato mais fiel da sua comunidade linguística.

Por enquanto, apenas três municípios brasileiros co-oficializaram outras línguas além do português: São Gabriel da Cachoeira (AM) línguas tukano, baniwa e nheengatu, Pancas (ES) e Santa Maria de Jetibá (ES) - língua pomerana (TORQUATO, 2010, p. 17-18). "Cooficializar uma língua significa que o município passa a ser oficialmente bilíngue, e que seus cidadãos podem construir suas vidas em duas línguas - a língua oficial da nação, o português, mas também a língua cooficial da comunidade" (OLIVEIRA, 2013, p. 6).

Nas políticas linguístico-educacionais internas, merecem consulta as propostas dos Parâmetros Curriculares Nacionais (PCN), o Exame Nacional do Ensino Médio (ENEM), a Prova Brasil, o Sistema Nacional 
de Avaliação da Educação Básica (SAEB), o Programa Nacional do Livro Didático (PNLD), para citar apenas as principais atualizações na área da educação básica. Esses exemplos demonstram que no Brasil as políticas linguísticas estão diretamente relacionadas à escola, à educação formal, como já destacou Oliveira (2005). Como as políticas linguísticas e educacionais aqui são bastante dependentes umas das outras, a execução nem sempre ocorre a contento, ou porque a elaboração não levou em conta características do grupo que as executa, ou por falta de clareza nas propostas de elaboração.

O processo de elaboração de uma política educacional eficaz consiste na fixação de uma série de objetivos, enunciados em termos concretos e práticos, que devem servir de guia para a ação imediata contendo mecanismos de avaliação. As medidas concretas de como se atingir as metas devem estar claramente explicitadas (CELANI, 2008, p. 18).

Após esse panorama geral sobre as políticas linguísticas, o próximo tópico introduz o tema mais central deste artigo: as políticas de internacionalização.

\section{Políticas de internacionalização da língua portuguesa: onde estamos}

Conforme explicitado anteriormente, entre os planejamentos executados pelos diferentes países de língua portuguesa, este artigo delimita a abordagem às ações brasileiras. Nesse contexto, a promoção da língua portuguesa no exterior se intensificou consideravelmente no fim do século 20 e início do século 21. O Ministério das Relações Exteriores (MRE) atua na divulgação do português em várias frentes. O Departamento Cultural do MRE busca aproximar o Brasil de outras nações, bem como divulgar a cultura brasileira e a língua portuguesa falada no Brasil.

Os primeiros Centros Culturais Brasileiros (CEBs) são da década de 1940 e desde essa época reforçam a divulgação internacional da língua portuguesa, até então restrita à tradução de livros.

Realizam-se também cursos de língua portuguesa em universidades do exterior, e o professor estrangeiro para tal função é denominado leitor. Os processos para o leitorado são definidos no Brasil pela Capes e MRE, e, em Portugal, pelo Instituto Camões. 
Os leitorados já sofreram várias alterações desde que surgiram, na década de 1960. "O Leitor hodierno não tem mais a característica informal, quase filantrópica de antes. Hoje os Leitores são profissionais qualificados que passaram por uma seleção rigorosa em nível nacional e internacional" (SÁ, 2009, p. 35).

De fato, os requisitos para a candidatura ficaram mais rígidos nesses pouco mais de 50 anos de processos de seleção. Após a comprovação de titulação - mestrado ou doutorado, conforme o caso-, hoje é necessário o comprovante de proficiência no idioma do país do leitorado ou em inglês, como língua franca. Os exames oficiais de proficiência - DELE para o espanhol, DELF para o francês, TOEFL e IELTS para o inglês, para mencionar apenas alguns - avaliam o conhecimento linguístico nas práticas de ler, escrever, ouvir e falar, o que requer uma boa familiaridade com o idioma.

Os leitores são selecionados em processos divulgados pela CAPES (Coordenação de Aperfeiçoamento de Pessoal de Nível Superior), e a universidade estrangeira toma a decisão final com base na pré-seleção feita no Brasil. Em 2014 havia 40 leitorados em 28 países. ${ }^{4}$

No Brasil, o processo de leitorado que ocorreu em 2014 abriu vagas para África do Sul, Argentina, Austrália, Cabo Verde, Canadá, Chile, China, Estados Unidos, França, Índia, Inglaterra, Israel, México e Moçambique.

Além de convênios de instituições do ensino superior com a Capes e a Divisão de Promoção da Língua Portuguesa (DPLP/MRE), há cursos de língua portuguesa em universidades estrangeiras, na graduação ou pós-graduação, como os citados na introdução deste artigo.

A criação de institutos e associações é uma tentativa de acompanhar a expansão contínua da língua portuguesa no exterior.

A Associação das Universidades de Língua Portuguesa (AULP), criada em 1986, investe no ensino da língua portuguesa pelo mundo. Em 2014, por exemplo, a AULP premiou a pesquisa que contribuiu para a aproximação de pelo menos dois países lusófonos.

A Comunidade dos Países da Língua Portuguesa (CPLP), por sua vez, surge em 1996, com o propósito de estimular a cooperação entre os Estados membros e reforçar a inserção da língua portuguesa em contextos internacionais.

${ }^{4} \mathrm{Cf} .<\mathrm{http}$ ://dc.itamaraty.gov.br/divisao-de-promocao-da-lingua-portuguesa-dplp-1>. 
Desde 1992, a Sociedade Internacional de Português Língua Estrangeira (SIPLE) vem reunindo, em eventos acadêmicos, profissionais que pesquisam a internacionalização linguística nos âmbitos de ensino e aprendizagem.

O Instituto Internacional da Língua Portuguesa (IILP) mantém o Portal do Professor de Português Língua Estrangeira / Língua Não Materna, além de outros projetos de divulgação linguística. Entre as ações concretas para a promoção da língua, destaca-se o Vocabulário Ortográfico Comum da Língua Portuguesa (VOC),

plataforma que alberga os instrumentos que determinam legalmente a ortografia da língua portuguesa. [...] Até ao final de 2014, o VOC integrará esses dados, substituindo os instrumentos de âmbito nacional existentes nos países participantes e permitindo que todos os falantes e estudantes da língua portuguesa tenham acesso livre a recursos oficiais comuns para aplicação das regras ortográficas $<$ http://www.iilp.cplp.org/voc/>.

Além das normas que regulamentam o uso ou que cuidam da defesa das línguas, há leis voltadas para a forma. É precisamente esse o caso do Acordo Ortográfico para os países da CPLP. Esse acordo fomenta a cultura de letramento e o mercado editorial, que deixa de ser fracionado por duas ortografias oficiais - a do Brasil e a de Portugal e demais países lusófonos. Essa duplicação da norma faz com que existam dois sistemas de busca no Google, dois corretores ortográficos, dois tradutores eletrônicos, numa sobreposição de interesses que não favorecem o usuário.

De acordo com o Ministério da Educação, o acordo implicará a cooperação internacional entre os oito países que falam a língua portuguesa ao estabelecer uma grafia oficial única do idioma. A medida também deve facilitar o processo de intercâmbio cultural e científico entre as nações e a divulgação mais abrangente da língua e da literatura (CORREA, 2009, p. 75).

Além disso, "o acordo é um instrumento político de construção de uma identidade comum" (FIORIN, 2009, p. 17).

No âmbito dos países do bloco do Mercosul, merece destaque o lançamento em 2006 do Programa de Mobilidade Acadêmica Regional para os Cursos Acreditados (MARCA), que possibilita que os 
estudantes estudem um semestre acadêmico em uma universidade de um país diferente do qual residem, contando com o reconhecimento das instituições (CARVALHO, 2012).

Ainda tendo em conta a América Latina, destaca-se a Universidade Federal da Integração Latino-Americana (UNILA), situada em Foz do Iguaçu, na fronteira Brasil-Argentina-Paraguai. Os alunos vêm de vários países latino-americanos. Desde 2012, a UNILA oferece 18 cursos de graduação e estrutura-se para oferecer pós-graduação.

A instituição [UNILA] constitui um ambiente multilíngue no qual a maioria das práticas desenvolve-se em português e espanhol, línguas oficiais da proposta educacional, mas com a presença de outros idiomas, como o guarani, o quéchua e o aimará, o que faz da universidade um lugar singular de encontro das línguas. Outro aspecto relevante nesse cenário é a diversidade cultural: as salas de aula são ponto de encontro não apenas de línguas diversas e suas variedades, mas também de diferentes formações socioculturais, constituindo um espaço educacional complexo, no qual as práticas de ensino / aprendizagem envolvem diferentes históricos escolares e de letramentos (CARVALHO, 2012, p. 478).

Ultrapassando os limites do Mercosul, o Celpe-Bras tornou-se experiência de projeção internacional. Trata-se do Exame de Certificação de Proficiência em Língua Portuguesa para Estrangeiros, aplicado em várias instituições brasileiras e estrangeiras, com o apoio do MRE. O exame adota a língua portuguesa e a cultura brasileiras, tendo se tornado referência no ensino de português para estrangeiros.

Cabe destacar que o exame [o Celpe-Bras] serviu de referência na elaboração de dois outros instrumentos de avaliação de proficiência: o Certificado de Proficiência em Libras, no Brasil, e o Certificado de Español - Lengua y Uso (CELU), na Argentina, que compartilham com o Celpe-Bras os pressupostos teóricos, a visão de linguagem e os objetivos (CARVALHO, 2012, p. 471).

Esse sumário das principais ações de promoção da língua portuguesa do Brasil no exterior mostra que houve progressos e vencemos a inércia dos anos 1960. Ainda assim, é preciso avançar. 


\section{Políticas de internacionalização da língua portuguesa: aonde precisamos ir}

As ações descritas acima demonstram claramente que o Brasil já avançou nas políticas de internacionalização. O exemplo mais notável é o da incrementação do processo de seleção dos leitores, cuja profissionalização afastou o nepotismo vigente até os anos 1960.

No plano das ações de internacionalização, uma das mais recentes é a criação da Rede Brasil Cultural, que abrange centros culturais, núcleos de estudos e leitorados em quatro continentes. No portal da internet,${ }^{5}$ os profissionais podem compartilhar conhecimento por meio de relato de experiências. Como exemplo, podem ser acessados materiais didáticos, notícias diversas e vídeos demonstrativos de aulas.

Essa iniciativa permite o diálogo, a troca de experiência entre os leitores mundo afora. No entanto, como sua criação é recente, de 2013, ainda não está suficientemente divulgada. Assim, sem compartilhar experiência, o leitor continua sempre "inventando a roda". Exemplo disso é a tomada de decisão sobre ferramentas básicas de trabalho: cada leitor escolhe um livro didático para adotar nas aulas, desconhecendo a experiência de colegas com aquela publicação. Não se trata meramente de análise de material didático, pois sobre isso há muito trabalho publicado: um site de busca na internet registra mais de 400 mil resultados para "análise livro didático português estrangeiros", nas suas diferentes delimitações. A questão é compartilhar narrativa de professores sobre o trabalho que a obra possibilitou em sala de aula. $\mathrm{Na}$ ausência de relatos de experiência com a obra, o material didático para o ensino de português para estrangeiros não se aprimora.

A situação transitória do vínculo do leitor também dificulta seu ofício. Como é sabido, os postos de leitorado têm a duração de dois anos, podendo ser renovados por mais um ou dois anos, dependendo da necessidade e do interesse da universidade contratante. Ou seja: o leitor é um profissional em trânsito constante. Essa permanente sensação de estar de passagem prejudica o aprofundamento no comprometimento profissional. Reestruturações, portanto, tendem a ser deixadas para o próximo leitor, num adiamento difícil de ser interrompido. A diluição do comprometimento claramente enfraquece a noção de autoria - "estou aqui de passagem".

${ }^{5}$ Cf. $<$ http://redebrasilcultural.itamaraty.gov.br> . 
Mesmo que receba um programa na IES, a formação do leitor será decisiva na forma de trabalhar o conteúdo. Os percursos profissionais anteriormente trilhados definirão o exercício didático das questões linguísticas e culturais, que serão trabalhadas de forma isolada ou integrada, dependendo dos saberes previamente vivenciados. Há, portanto, "[...] necessidade de um protocolo de ações comum, que forneça diretrizes mais claras para a política de ensino de português [...], reconhecendo, evidentemente, as especificidades de cada contexto" (DINIZ, 2012, p. 455).

Tudo indica que não será possível romper esses obstáculos sem complementar as linhas de pesquisa da pós-graduação, integrandoas às novas demandas do século 21. Ou seja: os programas de pós-graduação precisam ter disciplinas sobre políticas linguísticas, levando o tema aos profissionais que atuam na educação globalizada e que pesquisam sobre migração, minorias, inclusão, desconstrução das identidades monolíngues, planejamento linguístico, língua e poder etc. Esses temas excedem claramente o plano formal, a língua em si, e exigem que se incorporem reflexões externas à abordagem linguística.

O que ainda precisa ser feito é encorajar as partes envolvidas no sentido de refletir sobre essas questões de um ponto de vista político. Ou seja, o ensino / aprendizagem de línguas não pode ser discutido apenas do ponto de vista linguístico ou da perspectiva das teorias da aprendizagem. Ou ainda, sob o prisma do gosto pessoal ou pendor acadêmico. Essas questões também dizem respeito à cidadania (RAJAGOPALAN, 2008, p. 17).

$\mathrm{Na}$ sequência do texto, esse autor enfatiza por que deve ser dado um tratamento político às questões linguísticas: ensinar uma língua, materna ou estrangeira, pertence à esfera da política linguística. Práticas didáticas, afinal, são ações políticas por excelência.

Destaque-se que incorporar conteúdo sobre as políticas linguísticas implica flexibilizar o ensino de línguas, que, então, alarga as fronteiras de um ponto de vista interno e passa a agregar determinantes histórico-sociais. Esse viés deve começar na graduação, com análises que mostrem a língua como um sistema vivo, flexível e 
renovável a partir do uso na sociedade. Assim, esses conhecimentos se consolidariam na pós-graduação, que poderiam garantir o preparo para o futuro profissional atuar nas equipes definidoras das políticas linguísticas.

Com essa mudança, será possível intervir nas macropolíticas, ou seja: nas políticas de internacionalização linguísticas. Como os pesquisadores já demonstraram, é fundamental criar condições para as micropolíticas, ou seja: para a apropriação individual e / ou institucional da macropolítica.

Para construir políticas didático-linguísticas o professor deverá estar alicerçado pelas teorias diversas advindas de seu curso de formação profissional, bem como de conhecimentos globalizados e globalizantes a respeito de três concepções básicas:

a) Concepção de Língua / Linguagem;

b) Concepção de Políticas Linguísticas;

c) Concepção de Educação Linguística (PESSOA, 2007, p. 9).

O governo tem trabalhado nesse sentido, por exemplo, por meio do "Programa de Formação Intensiva Continuada para Professores de PLE (PROFIC PLE), coordenado pela DPLP [Divisão de Promoção da Língua Portuguesa]" (DINIZ, 2012, p. 455), cabendo aos programas de pós-graduação ampliar essa iniciativa, tal como vem começando a ocorrer.

Na UnB foi criado, em 1997, o primeiro curso de graduação em PLA [Português como Língua Adicional] (Português do Brasil como segunda língua: $<$ http://vsites.unb.br/il/liv/graduacao/pbsl.htm $>$. A universidade é pioneira na integração de ensino, pesquisa e extensão no Programa de Ensino e Pesquisa em Português para Falantes de Outras Línguas (PEPPFOL), oferecendo aulas à comunidade estrangeira e alunos conveniados, além de projetos de Formação Inicial Continuada para alunos do curso de Letras da $\mathrm{UnB}<\mathrm{http}: / /$ www.let.unb.br/peppfol/ $>$. Atuando também na área de PósGraduação, o foco de pesquisa é a formação de professores.

Além das IES mencionadas anteriormente, há várias que têm uma caminhada consolidada no ensino e que reúnem grupos de pesquisa em andamento, tais como: PUC-SP (através do NUPPLE), PUC-RJ, UFBA 
(através do PROPEEP), UFF, UFMG, UFPR (através do CELIN), UFRJ, UFSC. Dentre as que iniciaram mais recentemente na área de pesquisa em PLA estão: UEL (através do Laboratório de Línguas-IRCH), UFAM, UFSCar, UNIPAMPA, UNESP e USP (CARVALHO; SCHLATTER, 2011, p. 271-272).

Embora os linguistas devessem ter papel de destaque na definição das ações, por conhecerem a dinâmica social do grupo em questão, é nítida a ausência deles nos debates sobre políticas linguísticas (OLIVEIRA, 2005). O caminho, portanto, é preparar os futuros profissionais para atuar em ações conjuntas com as autoridades governamentais. Por conhecerem a área, por terem posse do saber competente, os pesquisadores podem contribuir no gerenciamento das políticas linguísticas.

Para internacionalizar a língua, precisamos internacionalizar a sua gestão, construindo de maneira conjunta a sua cadeia tecnológica e a coordenação diplomática da sua negociação global, reconhecendo a oportunidade de pensá-la e tratá-la como LÍNGUA POLICÊNTRICA. Preparado o terreno, torna-se o português nosso veículo privilegiado para o estabelecimento de relações econômicas e culturais no cenário mundial (OLIVEIRA, 2013a, p. 432).

O planejamento dessas ações conjuntas tem que ser abraçado pelos programas de pós-graduação, já que eles preparam a atuação dos novos profissionais, para que os atores envolvidos se apropriem do projeto e executem-no, pois "alguns estudos mais recentes em políticas de aquisição assumem que o professor é um agente central no desenvolvimento de uma política linguística" (CARVALHO; SCHLATTER, 2011, p. 265).

O problema é que a escola muda a passos muito lentos e não consegue acompanhar o ritmo das mudanças sociais. Essa constatação pode ser vista a mancheias, sobretudo no campo tecnológico, por exemplo: computadores e outras mídias são distribuídos às escolas de ensino fundamental, por meio de políticas públicas, mas na maioria delas não há pessoas que saibam lidar com as máquinas. Por trás da falta de formação técnica, há a atitude natural de resistência ao novo.

Os programas de pós-graduação, portanto, têm de assumir o papel indutor de promover mudanças, fazendo os futuros profissionais adentrarem a zona de risco - ou seja, vivenciarem a instabilidade de trabalhar com o novo. No tema aqui abordado, o novo se traduz em 
incorporar noções sobre as políticas linguísticas no projeto epistemológico da pós-graduação. Nesse novo encaminhamento, o conceito de cientificidade vai além de elaborar teorias abstratas ou descrever o sistema da língua, pois passa a integrar também considerações históricas, sociais e éticas, ampliando o conhecimento sobre o ensino de língua portuguesa para falantes de outras línguas em território nacional e no exterior. Em outras palavras: conhecer as motivações para a internacionalização permite encontrar formas de intervenção nas políticas linguísticas.

A resistência para essas mudanças é grande. Como a distribuição de bolsas e de recursos de fomento à pesquisa está diretamente relacionada à certificação de qualidade, definida por critérios cada vez mais austeros de avaliação, inovar pode trazer risco que é prudente evitar.

"A tendência é fazer sempre o mesmo" - continua Evans - "o desafio é formar pessoas inventivas que tomem a inovação como responsabilidade própria." [...] Evans prossegue: "Como podemos estar certos de que desempenhamos um papel importante para o progresso do sistema? Como podemos ter certeza de que não somos parte do problema? Estamos por demais estagnados em nossos métodos e resistimos em buscar outras maneiras de ver os problemas." "Em vez de dizer que toda responsabilidade é do governo" - e aqui poderíamos juntar às palavras de Evans "ou do sistema, do entorno cultural" -, "deveríamos nos esforçar por encontrar outras alternativas para exercer a liderança." (BRANDA, 2009, p. 208).

Essas alterações ajudam os profissionais a se sentir preparados para participar das esferas de decisão nas políticas linguísticas e educacionais. Tal participação é decisiva no aprimoramento das propostas, tal como ocorreu com os exemplos já mencionados, Língua Brasileira de Sinais e línguas indígenas, que só passaram a ter seus objetos de estudo respeitados após a intervenção de pesquisadores dessas áreas nas esferas governamentais de decisão. $\mathrm{O}$ foco é sempre zelar pelo êxito das propostas relacionadas à língua, seja no aspecto do ensino ou da divulgação, seja em pesquisas de diagnóstico ou de intervenção.

Assim, a pesquisa sobre políticas linguísticas desenvolvida na pós-graduação pode se centrar mais nos atores sociais e nas condições de produção, em sintonia com as propostas da linguística aplicada atual, na qual a 
[...] concepção de linguagem que recoloca, definitivamente, o ser humano, ser de linguagem, em meio a sua história e a sua cultura. Diferentemente da concepção de linguagem dominante no século 20, para a qual o sujeito é o ser da razão, no século 21 não é apenas a razão que o define mas também suas características sociais, culturais e históricas. (ARCHANJO, 2011, p. 622).

As estratégias de implantação dessas propostas dependem sobremaneira de ações conjuntas entre os programas de graduação e pós-graduação. Cabe, portanto, energia para aprofundar a inovação que a contemporaneidade requer. Um bom começo é conscientizar os futuros profissionais da língua portuguesa da necessidade de manter formação permanente, além de aprofundar a dimensão ética e de liderança. Em resumo, dar-lhes voz, para que eles possam atuar com autonomia nos diversos setores de sua profissionalização, o que inclui a criação das políticas linguísticas.

Dessa forma, os programas aproximam-se das modificações que já ocorreram no plano teórico, conforme as pesquisas da linguística aplicada foram se ampliando. Nos anos 1970, os estudos ainda buscavam a teorização desse novo campo de pesquisa e esmiuçavam formas de elaborar os aspectos técnicos da língua, bem como avaliar e executar os planejamentos. "Enfim, na década de 1970, os aspectos políticos envolvidos nas próprias propostas e ações dos planejadores eram pouco investigados; além disso, havia um certo padrão de tentativa de objetividade na pesquisa e na realização dos planejamentos" (TORQUATO, 2010, p. 10). Neste início do século 21, portanto, o cenário está preparado para que as pesquisas avancem na elaboração e execução das políticas linguísticas, superando a fase de investigação no tema.

Essa mudança de rota no objeto das pesquisas já havia sido prenunciada no VII Congresso Brasileiro de Linguística Aplicada, em 2004: "[...] começam a aparecer preocupações explícitas, embora tímidas, em discutir questões ligadas à ideologia, à política e à linguagem" (ARCHANJO, 2011, p. 624).

\section{Conclusão}

Após evidenciar a centralidade das línguas na organização mundial atual, o texto destacou a importância do multilinguismo no século 21. A partir disso, a exposição demonstrou diferentes momentos 
das políticas linguísticas, aqui abarcando "tanto as decisões tomadas no nível geral e macro, como também as atividades que contribuem para implementá-las" (RAJAGOPALAN, 2013, p. 29).

$\mathrm{Na}$ origem das políticas linguísticas domésticas, ressaltou-se a ordem do Marquês de Pombal, proibindo a língua geral. Verificou-se também a regulamentação de Libras, obtida por conta da insistência de profissionais que demonstraram a importância de políticas nesse campo. Mereceu destaque também a irrealidade da descrição linguística do Brasil, visto como país monolíngue. Finalmente, registrou-se a relação próxima entre política linguística e educação formal, pois no Brasil a tendência é manter estreitas relações entre esses dois temas.

No tocante à internacionalização da língua portuguesa, várias ações demonstraram superação da época em que a divulgação da língua portuguesa limitava-se à tradução de livros, a saber: os esforços do Departamento Cultural do Ministério das Relações Exteriores se traduzem na ampliação dos Centros de Estudos Brasileiros e dos leitorados. A constituição da Comunidade dos Países de Língua Portuguesa, a Associação das Universidades da Língua Portuguesa, a Sociedade Internacional de Português para Estrangeiros e o Instituto Internacional da Língua Portuguesa também ajudam a firmar o espaço internacional da língua portuguesa. $\mathrm{O}$ Vocabulário Ortográfico Comum, o Acordo Ortográfico, o Programa de Mobilidade Acadêmica Regional para Cursos Acreditados, a Universidade Federal da Integração Latino-Americana, a aplicação crescente do exame Celpe-Bras dentro e fora do Brasil, o interesse contínuo dos estrangeiros pela aprendizagem do português do Brasil, a recente criação do portal Rede Brasil Cultural exemplificaram práticas de internacionalização.

Essa breve historiografia das políticas linguísticas no cenário brasileiro e em contexto de internacionalização constatou algumas ideias que orientam e condicionam o exercício das políticas linguísticas. Um aspecto que não pode ser esquecido é que, em geral, os políticos não são linguistas, e os linguistas não são políticos. Aliás, os Ministros da Educação do período de 2004 a 2014 têm formação em Economia ou em Direito. A tendência, portanto, é prevalecerem interesses como a criação de escolas, projetos visíveis que facilmente se convertem em votos futuros, em detrimento de investimentos em bens intangíveis, como a formação de professor e a qualidade de ensino.

Para conciliar essas diferentes vozes, é fundamental que os pesquisadores de língua e linguagem passem a atuar de forma sistemática 
nas esferas de decisão governamental, que afinal não são neutras e retratam claramente as relações de poder. A chance de isso ocorrer depende de os profissionais serem preparados para essa atuação.

Em consequência, defendo renovar as linhas de pesquisa da pós-graduação, por exemplo, incorporando no seu projeto pedagógico conteúdos e problematizações sobre o tratamento das questões linguísticas em viés ideológico e ético. Isso permite que o campo de saber das políticas linguísticas defina suas fronteiras e legitime sua identidade. O próximo passo é alcançar representatividade como saber científico instituído. Compreendendo a linguagem como ação social, os agentes são preparados para perceber sua atuação como ação política e compreender as relações de poder que se estabelecem no planejamento e na execução das políticas educacionais e linguísticas.

Outra sugestão para o avanço da internacionalização da língua portuguesa é estreitar a troca de experiência entre os leitores, para aperfeiçoamento contínuo do trabalho realizado. Esse encaminhamento já foi iniciado pela criação da Rede Brasileira de Leitores, devendo ser expandida nos próximos anos em redes internas - contato entre os leitores da mesma instituição - e em redes externas-, contato entre leitores de diferentes instituições.

O desafio, portanto, é inovar, visando à maior eficiência na formação dos profissionais de línguas e suas respectivas literaturas e culturas. Em resumo, proporcionar uma formação integrada às questões sociopolíticas do seu tempo, que lhes permita responder criticamente aos problemas da sua área de atuação.

\section{Referências}

ALTENHOFEN, C. V. Política linguística, mitos e concepções linguísticas em áreas bilíngues de imigrantes (alemães) no Sul do Brasil. In: RILI II, v.1 (3), p. 83-93, 2004. Disponível em: $<$ http://www.iberoamericanalibros.com/ files/ejemplo_por.pdf $\geq$. Acesso em: 24 ago. 2014.

ARCHANJO, R. Linguística aplicada: uma identidade construída nos CBLA. In: Revista Brasileira de Linguística Aplicada. Belo Horizonte: Faculdade de Letras da UFMG, v. 11, n. 3, p. 609-632, 2011.

BALDAUF JR., R. B. Introduction - language planning: where have we been? Where might we be going? In: Revista Brasileira de Linguística Aplicada. Belo Horizonte, UFMG, v. 12, n. 2, p. 233-248, 2012. 
BOURDIEU, P. A economia das trocas linguísticas. São Paulo: Edusp, 1998. BRANDA, L. A. A aprendizagem baseada em problemas - o resplendor tão brilhante de outros tempos. In: ARAÚJO, U. F.; SASTRE, G. (Org.). Aprendizagem baseada em problemas no ensino superior. São Paulo: Summus, 2009. p. 205-236.

CALVET, L. J. As políticas linguísticas. São Paulo: Parábola, 2007.

CARVALHO, S. da C. Políticas de promoção internacional da língua portuguesa: ações na América Latina. In: Trabalhos em Linguística Aplicada, Campinas, v. 51, n. 2, p. 459-484, jul./dez., 2012.. Disponível em: $<$ http://www.scielo.br/pdf/tla/v51n2/a10v51n2.pdf $>$. Acesso em: 11 maio 2015.

CARVALHO, S. da C.; SCHLATTER, M. Ações de difusão internacional da língua portuguesa. In: Cadernos do IL. Porto Alegre, n. ${ }^{\circ} 42$, p. $260-$ 284, jun. 2011. Disponível em: <http://www.seer.ufrgs.br/index.php/ cadernosdoil/article/view/26027/15240>. Acesso em: 17 ago. 2014.

CELANI, M. A. A. A relevância da linguística aplicada na formulação de uma política educacional brasileira. In: FORTKAMP, M. B. M.; TOMITCH, L. M. (Org.). Aspectos da linguística aplicada: estudos em homenagem ao Prof. Hilário Inácio Bohn. 2. ed. Florianópolis: Insular, 2008. p. 17-32.

CORREA, D. A. Política linguística e ensino de língua. In: Calidoscópio, v. 7, n. 1, p. 72-78, jan./abr. 2009. Disponível em: <http://revistas. unisinos.br/index.php/calidoscopio/article/view/4856>. Acesso em: 24 ago. 2014.

CUNHA, R. B. Políticas de línguas e educação escolar indígena no Brasil. In: Educar em Revista, Curitiba: Editora UFPR, p. 143-159, 2008. Disponível em: $<$ http://www.scielo.br/pdf/er/n32/n32a11.pdf $>$. Acesso em: 20 ago. 2014.

DINIZ, L. R. A. Política linguística do Estado brasileiro para a divulgação do português em países de língua oficial espanhola. In: Trabalhos em Linguistica Aplicada, Campinas, v. 51, n. 2, p. 435-458, jul./dez. 2012. Disponível em: <http://www.scielo.br/scielo.php?pid=S0103$18132012000200009 \&$ script=sci_arttext $>$. Acesso em: 23 set. 2014.

. O "Quadro Europeu Comum de Referência para as Línguas" - sujeitos, estados nacionais e mercado. In: Anais do Seta, Campinas: 
Unicamp, p. 363-369, 2007. Disponível em: <http://revistas.iel. unicamp.br/index.php/seta/article/view/274/236>. Acesso em: 12 nov. 2014.

FIORIN, J. L. O acordo ortográfico: uma questão de política linguística. In: Revista Veredas, Juiz de Fora, PPG Linguística / UFJF, v.1, n.9, p. 1-19, 2009. Disponível em: <http://www.ufjf.br/revistaveredas/ files/2009/12/artigo012.pdf>. Acesso em: 29 ago. 2014.

FRITZEN, M. P. "Ia na escola alemã e de um dia pro outro fechou. E nós não sabíamos falar o português": refletindo sobre as políticas linguísticas em contexto de língua minoritária. In: Revista Linguagem \& Ensino, Pelotas, v.15, n.1, p. 113-138, jan./jul. 2012. Disponível em: $<$ http://rle. ucpel.edu.br/index.php/rle/article/viewFile/480/426>. Acesso em: 18 ago. 2014.

HAAG, C. Diversidade brasileira. In: Revista Fapesp, São Paulo: Fapesp, p. 86-89, jul. 2010.

INSTITUTO CAMÕES. Disponível em: $<$ http://www.instituto-camoes. pt>. Acesso em: 4 jun. 2015.

LUNA, J. M. O Army Method e o desenvolvimento da linguística aplicada nos Estados Unidos. In: Revista Brasileira de Linguística Aplicada, Belo Horizonte: Faculdade de Letras da UFMG, v. 12, n. 1, p. 31-48, 2012.

LUQUETTI, E. C. F.; MOURA, S. A. de; CASTELANO, K. L. Políticas linguísticas: análise de polêmica pública em torno da adoção de livro de ensino de português para jovens e adultos pelo MEC. In: Agenda Social, v. 5, n. 3, p. 13-29, set./dez., 2011,. Disponível em: <http://www.uenf.br/ Uenf/Downloads/Agenda_Social_8802_1337692953.pdf $>$. Acesso em: 24 ago. 2014.

MENDES, E. O ensino de português como língua de herança - entrevista a M. Cardoso, 12 abr. 2014. Disponível em: <http://iilp.wordpress. com/2014/04/12/entrevista-edleise-mendes/>. Acesso em: 11 maio 2015.

OLIVEIRA, G. M. de. Políticas linguísticas como políticas públicas. 2013. Disponível em: <http://e-ipol.org/wp-content/uploads/2013/06/ Politicas_linguisticas_e_Politicas_publicas.pdf $>$. Acesso em: 24 ago. 2014.

. Política linguística e internacionalização: a língua portuguesa no mundo globalizado do século XXI. In: Trabalhos em Linguística Aplicada, Campinas, n. ${ }^{\circ}$ 52.2, p. 409-433, jul./dez. 2013a. Disponível 
em: <http://www.scielo.br/pdf/tla/v52n2/a10v52n2.pdf>. Acesso em: 27 set. 2014.

. de. Política linguística na e para além da educação formal. In: Revista Estudos Linguísticos, n. 34, p. 87-94, 2005. Disponível em: $<$ http://www.gel.org.br/estudoslinguisticos/edicoesanteriores/4publicaestudos-2005/4publica-estudos-2005-pdfs/1-convidado-gilvan.pdf $>$. Acesso em: 18 ago. 2014.

PASSOS, J. L. Literatura brasileira a distância - entrevista a C. Ploennes. In: Revista Lingua Portuguesa, São Paulo: Segmento, Ano 9, n. 107, p. 12-16, set. 2014.

PESSOA, M. do S. Concepções de linguagem e políticas linguísticoculturais: aproximações e/ou afastamentos na educação linguística. 2007. Disponível em: <http://www.oi.acidi.gov.pt/docs/Seminario LPIntegracao/8_Maria_Socorro_Pessoa.pdf $>$. Acesso em: 23 ago. 2014. RAJAGOPALAN, K. Política linguística: do que se trata afinal? In: NICOLAIDES, C. et al. (Org.) Política e políticas linguísticas. Campinas: Pontes, 2013. p. 19-42.

RAJAGOPALAN, K. Política linguística e a política da linguística. In: SIMÕES, D.; HENRIQUES, C. C. (Org.). Língua portuguesa, educação \& mudança. Rio de Janeiro: Europa, 2008. p. 11-22.

SÁ, D. S. O leitorado brasileiro em Manchester: política linguística e ensino de português como língua estrangeira. In: Cadernos de Letras da UFF- Dossiê difusão da língua portuguesa, n. 39. p. 31-40, 2009. Disponível em: <http://www.cadernosdeletras.uff.br/images/stories/ edicoes/39/artigo1.pdf>. Acesso em: 18 ago. 2014.

SILVA, M. V. da. História das ideias linguísticas: o Estado, as instituições, as políticas. 2007. Disponível em: <http://www.ucb.br/sites/100/165/ artigosecomunicacoes/1historia.pdf $>$. Acesso em: 18 ago. 2014.

SINGH, N. K.; ZHANG, S.; BESMEL, P. Globalization and language policies of multilingual societies: some cases studies of South East Asia. In: Revista Brasileira de Linguística Aplicada. Belo Horizonte, UFMG, v. 12, n. 2, p. 349-380, 2012.

TONDATO, M. P. Telenovelas exportadas. Disponível em: <http://www. portcom.intercom.org.br/pdfs/0c6f28cc27f89a01f7c94d145f361665. PDF>. Acesso em: 8 set. 2014. 
TORQUATO, C. P. Políticas linguísticas, linguagem e interação social. In: Revista Escrita, Rio de Janeiro: PUC-Rio, n. 11. p. 1-29, 2010. Disponível em: <http://www.maxwell.vrac.puc-rio.br/16370/16370.PDF>. Acesso em: 21 ago. 2014. 